\title{
TUBE FORMATION BY POMATOCEROS TRIQUETER (POLYCHAETA)
}

\author{
By R. H. HedLEY ${ }^{\star}$ \\ Department of Zoology, King's College, University of Durham, Newcastle upon Tyne I
}

(Text-figs. I-I8)

The serpulid polychaete Pomatoceros triqueter Linnaeus, I758, with its white calcareous tube, is common on all rocky coasts around the British Isles. Normally $2-3 \mathrm{~cm}$ in length, and exceptionally $6 \mathrm{~cm}$, the tubes are found attached to rocks, stones, and shells. Occasionally specimens obtained by dredging in offshore waters have tubes which, although still attached, grow away from the substratum.

This paper is the third in a series on serpulid tube formation. Earlier accounts (Hedley, 1956a, $b$ ) describe the calcium-secreting glands of four British serpulids, together with an account of the organic component of the tube of $P$. triqueter.

\section{DESCRIPTION OF THE TUBE}

After a free-living larval stage $P$. triqueter settles on the substratum and secretes a semi-transparent tube (Segrove, I94I). Initially the tube is shorter than the worm and only after a rapid increase in tube length is the animal completely enclosed. Tubes at this stage have thin walls which according to Dons (I927) are non-calcified and which are found by Segrove (I94I) to consist of mucus and calcareous matter. Subsequent growth by the addition of calcareous material to the anterior end of this fragile tube results in the heavily calcified tube of the adult worm.

The adult tube is invariably curved in one or more directions and although straight tubes do occur they are extremely rare. On the upper surface there is a keel (Fig. I), which varies slightly in size and position and which may project as a point beyond the anterior opening. Two other parts of the tube are referred to here as the lateral surface deposit and the anterior surface deposit (Fig. 3). The former is found on each side of the tube mass and the latter is a thin deposit on the substratum at the anterior end of the tube.

A series of ridges on the outer surface of the tube (Figs. I, 2) give a false and superficial appearance of a series of growth rings. Previously the tube has been thought of as a series of calcareous rings (Potts, teste Robertson \& Pantin, 1938), a view probably influenced by the surface ridge appearance, and also by

* Present address, Department of Zoology, British Museum (Natural History). 
the fact that worms removed from their tubes produce hoop-shaped calcareous rings in the fold of the collar.

During early spring pure white additions to the anterior ends of the tube develop. These seldom appear in the winter, although if the worms are brought from the shore into the laboratory deposition quickly commences. As a result of such discontinuous deposition there are regions, at irregular intervals along the tube, which indicate cessation (and the beginning) of deposition phases. These are noticeable external features which occur perhaps two or three times
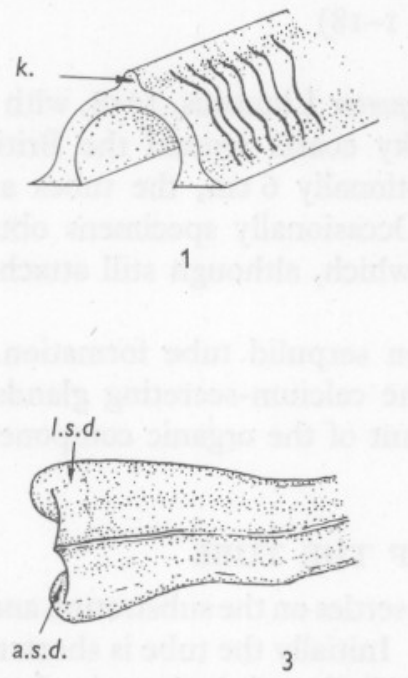

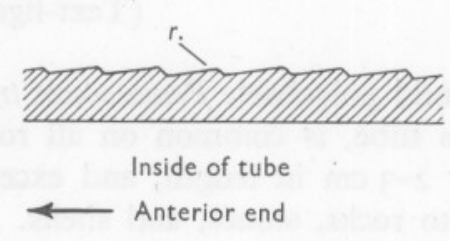

2

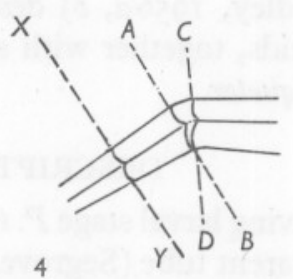

Fig. I. Diagram of the anterior end of a tube showing the position of the keel and of the ridges along the tube. $k .$, keel.

Fig. 2. Diagram of a section through the wall of the tube illustrating the ridges seen on the outer surface of the tube. $r$., ridge.

Fig. 3. A top view of the tube. l.s.d., lateral surface deposit; a.s.d., anterior surface deposit. Fig. 4. Diagram to illustrate a process of tube growth which is discussed in the text.

along a $3 \mathrm{~cm}$ tube. The end of a deposition phase which begins at a level $X-Y$ (Fig. 4) might be expected at a level $A-B$. This will occur only when both sides of the tube receive an equal amount of calcareous material. In many tubes one side develops to a greater extent than the other, for example, to a level $C-D$. At the onset of the next phase of deposition the tube will develop as shown only if an equal amount of calcareous material is deposited on both sides.

Tubes are usually incomplete in cross-section and appear as arches over the substratum (Fig. 5). Faouzi (I93I) infers from the arrangement of the collar that the worm can never be completely surrounded by the tube. Apparently this is not the case as tubes are sometimes found which are complete in crosssection (Fig. 6). More convincing examples are provided by clusters of 
$P$. triqueter, sometimes dredged in offshore waters, the tubes of which grow away from the substratum and are completely round in cross-section (Fig. 7).

Cavities in the thick lateral portions at the base of the tube (Fig. 9) have been observed and the resulting economy of tube material commented upon (McIntosh, I923; Thomas, I940). It has been suggested that other holes which penetrate the side of the tube may be used for the intake and outlet of water

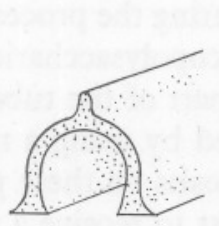

5

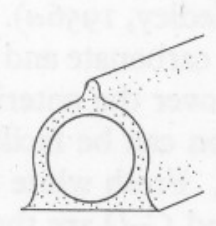

6

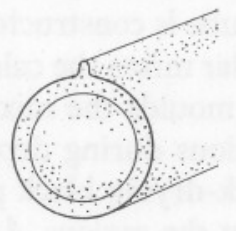

7

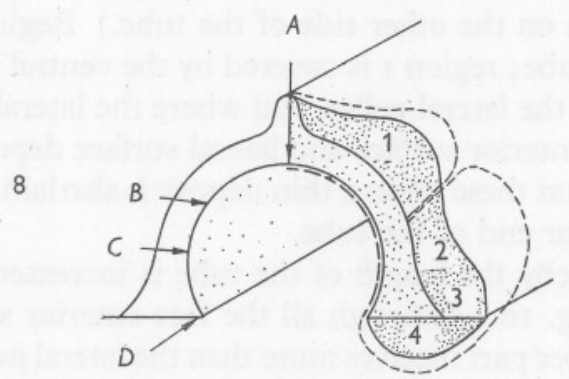

Fig. 5. Diagram of an attached portion of tube which is incomplete in cross-section.

Fig. 6. Diagram of an attached portion of tube which is complete in cross-section.

Fig. 7. Diagram of a portion of tube which has grown away from the substratum and which is completely round in cross-section.

Fig. 8. Diagram of the anterior end of the tube with the broken line indicating the region covered by the collar of the worm (drawn on one side of the tube only). Other areas which are labelled are explained in the text.

for respiratory purposes (Thomas, I940). These holes, however, are not a regular feature of the tube, and when present, they are few in number and are confined to the early formed and thinner regions of the tube. They are in fact minor variations of the cavities just described, which occasionally are without an external covering and appear as holes in the side of the tube. Only on rare occasions is a hole of this kind continuous through the tube wall into the lumen. 


\section{THE MODE OF DEPOSITION}

During deposition the worm's branchial crown and operculum project out of the anterior tube opening, and the ventral and lateral collars are folded back over the surface of the tube. In the fold formed by the collar two glands, one on each side of the peristomium, produce calcium carbonate granules, and these together with the secretion of mucopolysaccharide from the unicellular glands in the ventro-lateral peristomial epithelium constitute the material of which the tube is constructed (Hedley, I956 $a$ ). During the process of deposition the collar mixes the calcium carbonate and mucopolysaccharide, and concomitantly moulds the mixture over the anterior part of the tube.

Observations during deposition can be facilitated by using a tube painted with a quick-drying black paint. Fresh white deposits on these preparations indicate that the regions $A-B$ and $C-D$ are the first to receive a new deposit (Fig. 8). Following this, further deposits appear on the areas $1,2,3,4$, and on region $B-C$. (Fig. 8 is diagrammatic, and where reference is made to an area on one side of the tube it should be understood that a corresponding deposit is also being laid down on the other side of the tube.) Region $A-D$ is the free anterior face of the tube; region I is covered by the ventral collar; regions 2,3 and 4 are covered by the lateral collar, and where the lateral collar overlaps on the substratum the anterior surface and lateral surface deposits are found. In addition to deposits on these areas a thin deposit is also laid down on the inside surface of the anterior end of the tube.

The process whereby the length of the tube is increased can be described with reference to Fig. Io. Although all the free anterior surface is receiving new material the upper part receives more than the lateral parts, with the result that the upper part grows forward to a level $X-Y$. Meanwhile the lateral and anterior surface deposits become thicker, but do not advance beyond their limit $L-M$ until the worm readjusts the position of the lateral collars. This readjustment is a definite move forward so that with subsequent deposition a very thin anterior surface deposit is found with a limit $O-P$. During this phase the upper part of the tube becomes thicker but not longer. This cycle is now repeated. The whole process involves a relatively rapid forward movement of the collar followed by a stationary phase during which the tube thickens and a small ridge appears on the tube surface. These are the ridges which have been described (Fig. I).

The presence of cavities in the base of attached tubes (Fig. 9) is probably correlated with the precise arrangement of the lateral collars and the notopodial chaetae of the peristomium. The first sign of a cavity is in position $A$ (Fig. I0), where, if direct observation were possible, one would expect to find the notopodial chaetae. These bristles normally move in and out of the chaetal sac and it is suggested that this constant movement prevents the formation of a deposit. With the thickening of the lateral and anterior surface deposits the depression 
or hole $A$ becomes deeper and surrounded by tube material. When the lateral collar moves forward the chaetae do likewise and are no longer associated with the hole just formed. The chaetae now prevent a deposit forming in position $B$, while the hole formed at $A$ is covered over by a deposit being laid down on the inside of the tube. This explanation of the formation of the cavities remains speculative in the absence of direct observations.

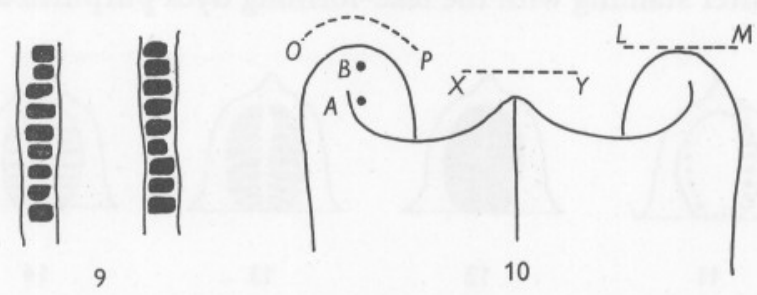

Fig. 9. Diagram of part of a tube with the roof removed to show the cavities which are present in the base of each side.

Fig. I0. Diagram of a top view of the anterior end of a tube; for an explanation of the lettering see text.

\section{THE POSTERIOR CALCAREOUS GRATING}

The tubes of $P$. triqueter, in the intertidal zone, are very often damaged at the posterior end. Almost invariably, in such cases, a single calcareous grating or plate (Fig. II) is present inside the tube, just anterior to the damaged region (McIntosh, 1923; Thomas, 1940).

After damaging the posterior end of a tube, and removing the debris, a grating is formed after approximately $6-24 \mathrm{hr}$. The first stage is the secretion by the worm of a mucous septum inside the posterior end of the tube. This is followed by the appearance of a number of thin calcareous ribs in the mucous septum (Fig. I2) which become thicker and opaque, while the mucus between them becomes translucent and white (Fig. I3). Calcification continues (Fig. I4), and finally the typical grating is formed (Fig. II) almost closing the posterior end of the tube.

The grating is a curved structure and this is correlated with the ventral flexure of the posterior end of the abdomen as the worm lies on its back in the tube (Fig. I5). The flexed region of the abdomen acts as a mould in which the calcareous grating is formed. The transverse calcareous ribs correspond in position to the intersegmental grooves (Fig. I6), while the main dorso-ventral rib corresponds to the mid-ventral ciliated groove of the abdomen. The holes in the grating correspond in position to the lateral swollen neuropodia of the abdominal segments (Figs. 16, I8) from which relatively long chaetae project and prevent the complete calcification of the grating.

Attempts have been made to locate the cells or tissues responsible for the secretion of the calcareous material required for the production of a grating. 
Worms were fixed in a neutral solution, either ethyl alcohol or an alcoholformalin mixture, and longitudinal (Fig. I7) and transverse sections (Fig. I8) of the posterior end of the abdomen were treated with the following methods. Staining with toluidine blue for the detection of mucous cells (Sylven, 194I); staining with purpurin (Lison, 1936) and gallamine blue (Stock, 1949) for the detection of calcium; and incineration to locate calcium ash. Negative results are obtained after staining with the lake-forming dyes purpurin and gallamine

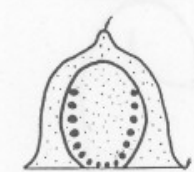

11

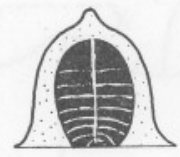

12

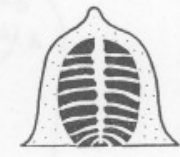

13

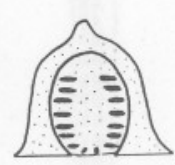

14

Fig. Ir. Diagram of a calcareous grating which is found inside, and almost closes, the posterior end of the tube.

Figs. 12-I4. Diagrams of three stages in the formation of a calcareous grating.

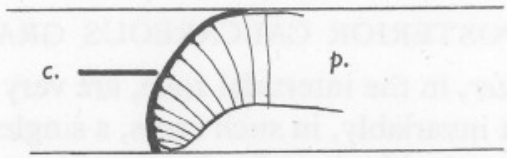

Fig. I5. Diagram to show the ventral flexure of the posterior end of the worm's abdomen and the position of the calcareous grating. p., posterior end of worm; $c$., calcareous grating.

blue. Other sections stained with toluidine blue and compared with alternate sections, which are incinerated, show that the ventral epithelial mucous cells contain a large amount of calcium. These cells are very numerous in the ventral epithelium compared with the dorsal epithelium where they occur only occasionally. Further comparisons of stained and incinerated sections were made in an attempt to find cells which do not contain mucigen and which have a high calcium content. Such cells were not demonstrated.

It is apparent from the position and form of the calcareous grating that the calcium originates from some tissue in the posterior end of the abdomen. It is most unlikely that the dorsal epithelium is involved (bearing in mind that a serpulid lies in its tube ventral surface uppermost), thus the ventral epithelium is most probably the source of the calcareous material. From the results obtained it appears that there are no obvious calcium-secreting organs in the posterior abdomen and it seems likely that the unicellular mucous glands of the ventral epithelium are responsible. It is worthy of mention that the rectum contains a large number of mucous cells and that the calcium-ash content of these is as great as that of the ventral epithelial mucous cells. The contents of 
the rectum pass out via the anus and then along the ventral ciliated groove, and so the rectum may contribute some material towards the formation of the calcareous grating.

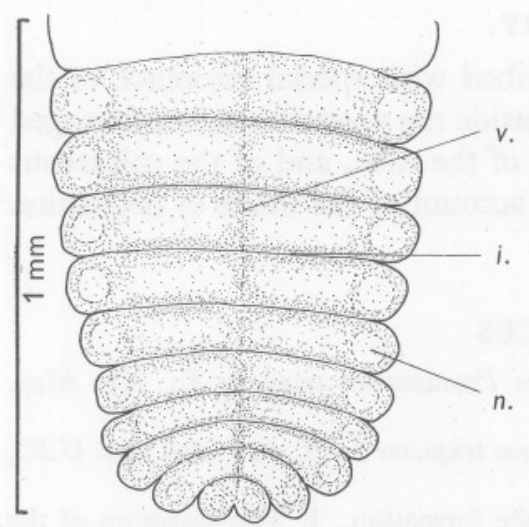

16

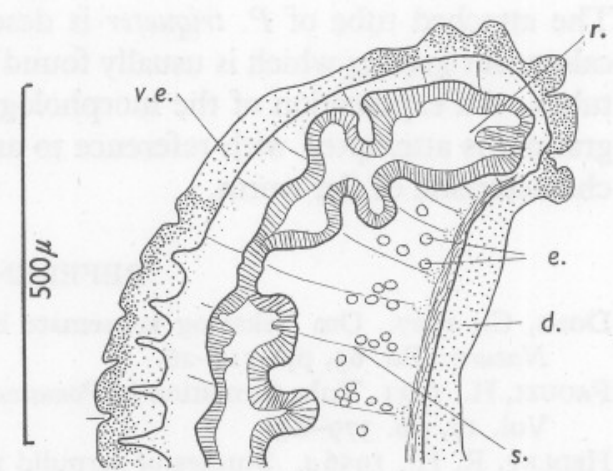

17

Fig. I6. Diagram of the ventral surface of the ten most posterior segments of the abdomen. $v$., mid-ventral ciliated groove; $i$., intersegmental groove; $n$., neuropodial swelling.

Fig. 17. Diagram of an oblique longitudinal section through the posterior end of the abdomen. The mucous secreting areas of the epithelium are more heavily dotted. v.e., ventral epithelium; $r$. , rectum; e., eggs, d., dorsal epithelium; s., intersegmental septum.

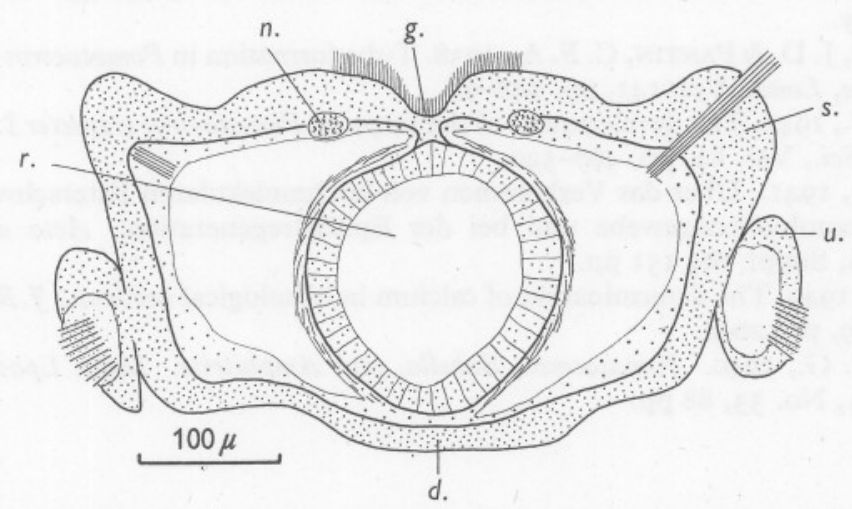

Fig. 18. Diagram of a transverse section through the posterior end of the abdomen. $d$. , dorsal epithelium; $g$., ventral ciliated groove; $n$., ventral nerve cord; $r$., rectum; $s$., swollen neuropodium with chaetae; $u$., notopodium with uncinus.

This paper is an account of part of the work carried out during the period of tenure of a grant from the Department of Scientific and Industrial Research. The author wishes to thank Prof. A. D. Hobson for the facilities and help given while working in his department, and also $\mathrm{MrN}$. Tebble for suggestions at the manuscript stage. 
Some of the work on serpulid tube formation was carried out at the Laboratory, Plymouth, and the author appreciates the facilities provided by the Director and his staff.

\section{SUMMARY}

The attached tube of $P$. triqueter is described with special reference to the calcareous grating which is usually found inside the posterior end of damaged tubes. An explanation of the morphology of the tube, and of the calcareous grating, is attempted with reference to an account of the mode of deposition characteristic of the worm.

\section{REFERENCES}

Dons, C., 1927. Om Vekst og voksemate hos Pomatoceros triqueter L. Nyt Mag. Naturv., Bd. 65, pp. III-26.

FaouzI, H., I93I. Tube formation in Pomatoceros triqueter L. F. mar. biol. Ass. U.K., Vol. 17, pp. 379-84.

Hedley, R. H., I $956 a$. Studies of serpulid tube formation. I. The secretion of the calcareous and organic components of the tube by Pomatoceros triqueter. Quart.F. micr. Sci., Vol. 97, pp. 4I I-9.

I $1956 \mathrm{~b}$. Studies of serpulid tube formation. II. The calcium secreting glands in the peristomium of Spirorbis, Hydroides, and Serpula. Quart. F. micr. Sci., Vol. 97, pp. 42 I-7.

Lison, L., I936. Histochemie animale. Paris: Gauthier-Villars.

McIntosh, W. C., 1923. The British Marine Annelids, Vol. 4, 538 pp. London: Ray Society.

Robertson, J. D. \& Pantin, C. F. A., I938. Tube formation in Pomatoceros triqueter L. Nature, Lond., Vol. I4I, pp. 648-9.

Segrove, F., I94I. The development of the serpulid Pomatoceros triqueter L. Quart. F. micr. Sci., Vol. 82, pp. 467-540.

SYLVEN, B., I94I. Uber das Verkommen von hochmolekularen Esterschwelfelsauren im Granuluationsgewebe und bei der Epithelregeneration. Acta chir. scand., Bd. 86, Suppl. 66, I5I pp.

Sтоск, A., 1949. The determination of calcium in histological sections. F. R. micr. Soc., Vol. 69, pp. 20-4.

Thomas, J. G., I940. Pomatoceros, Sabella, and Amphitrite. Mem. Lpool mar. biol. Comm., No. 33, 88 pp. 